\title{
Effects of real-time feedback training on weight shifting during golf swinging on golf performance in amateur golfers
}

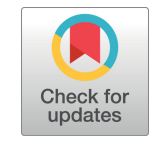

\author{
Ji-Hyun Hwang ${ }^{a}$, Ho-Suk Choi ${ }^{b}$, Won-Seob Shin ${ }^{a, b}$ \\ ${ }^{a}$ Department of Physical Therapy, Graduate School of Health and Medical, Daejeon University, Daejeon, Republic of Korea \\ ${ }^{b}$ Department of Physical Therapy, College of Health and Medical Science, Daejeon University, Daejeon, Republic of Korea
}

\begin{abstract}
Objective: The purpose of this study was to examine the effects of real-time visual feedback weight shift training during golf swinging on golf performance.

Design: Repeated-measures crossover design.

Methods: Twenty-sixth amateur golfers were enrolled and randomly divided into two groups: The golf swing training with real-time feedback on weight shift (experimental group) swing training on the Wii balance board (WBB) by viewing the center of pressure (COP) trajectory on the WBB. All participants were assigned to the experimental group and the control group. The general golf swing training group (control group) performed on the ground. The golf performance was measured using a high-speed 3-dimensional camera sensor which analyses the shot distance, ball velocity, vertical launch angle, horizontal launch angle, back spin velocity and side spin velocity. The COP trajectory was assessed during 10 practice sessions and the mean was used. The golf performance measurement was repeated three times and its mean value was used. The assessment and training were performed at 24-hour intervals.
\end{abstract}

Results: After training sessions, the change in shot distance, ball velocity, and horizontal launch angle pre- and post-training were significantly different when using the driver and iron clubs in the experimental group $(p<0.05)$. The interaction time $\times$ group and time $\times$ club were not significant for all variables.

Conclusions: In this study, real-time feedback training using real-time feedback on weight shifting improves golf shot distance and accuracy, which will be effective in increasing golf performance. In addition, it can be used as an index for golf player ability.

Key Words: Golf, Sensory feedback, Weight bearing

\section{Introduction}

Golf uses various clubs to hit balls into the hole cups, and a regular golf course consists of 18 holes. Golf has increased in popularity with economic growth, and this popularity and interest has led golfers to pursue improved performance.

The motion of hitting the ball is divided into three steps: swinging the club, head to ball affect energy transfer in collisions, and ball flight. A set of golf clubs typically consists of wood, at least 1 hybrid, seven iron, at least one wedge, and a putter. The golfer selects the appropriate club according to the condition of the course and distance from the hole [1].
The effects on the performance of the golfer require specific strength, swing stability, shot distance, mental power, judgment, and equipment $[2,3]$. The goal of the golfer is to send the golf ball far and accurately in the game, which has a significant impact on game outcome. In particular, the strength of the golfer plays an important role in increasing the shot distance in the process of performing the golf shot. The muscle strength of the trunk are related to club head speed [4], and lower extremity and shoulder muscle strength have been reported to affect handicap and target accuracy [5].

An understanding of forces and torques applied by the feet to the ground during the golf swing is vital for achieving

Received: 27 October, 2017 Revised: 6 December, 2017 Accepted: 7 December, 2017

Corresponding author: Won-Seob Shin

Department of Physical Therapy, Graduate School of Health and Medical, Daejeon University, 62 Daehak-ro, Dong-gu, Daejeon 34520, Republic of Korea Tel: 82-42-280-2294 Fax: 82-42-280-2295 E-mail: shinws@dju.kr

(c) This is an Open-Access article distributed under the terms of the Creative Commons Attribution Non-Commercial License (http://creativecommons.org/licenses/ by-nc/4.0) which permits unrestricted non-commercial use, distribution, and reproduction in any medium, provided the original work is properly cited.

Copyright $\odot 2017$ Korean Academy of Physical Therapy Rehabilitation Science 
proper mechanics and optimal performance. Several key factors for improving golf performance have been identified. Skilled players with lower golf scores and swing analyzed had higher club head velocity, higher ball vertical launch angle, lower standard deviation of ball velocity, and faster body-twist angular velocity [3]. The golf swing is a complex movement which, to a large extent, is influenced by the action of the feet. To better understand proper swing mechanics, a number of researchers have studied the reaction between the golfer and the ground [6]. During the golf swing, the body is subjected to weight shift with rotational motion, and this weight transfer ability is used as a tool for golf players to evaluate their performance [7]. In particular, amateur golfers need training in stability and accuracy as well as swinging practice. Compared with elite golfers, amateur golfer showed a difference in static balance and weight transfer ability [8,9]. Analysis of the swing of the Professional Golfers' Association golfer and the elite golfer, the center of pressure (COP) trajectory was different from the amateur golf player and the COP trajectory range in the anteroposterior posterior (AP) was lower $[9,10]$.

Previous studies on weight shifting have studied the use of prop exercises or games for balance training and use of a force plate that receives COP information on the body weight $[11,12]$. Feedback training is to correct performance for effective outcomes for during exercise and training, and the method of the feedback is provided by verbal command, hand contact, visual information or auditory signals [13-15]. Visual feedback can be integrated with afferent information coming from the vestibular and somatosensory senses, contributing to and improving postural control [16]. In the previous study, as a result of comparing with or without visual feedback, the amount of COP trajectory decreased with feedback [17].

The importance of weight shifting during golf swinging has been studied, but studies using weight shift training and observing the movement of the COP are lacking. Therefore, the purpose of this study was to investigate whether the golfer's swing performance was effective by applying real-time visual feedback training on weight shifting to amateur golfers.

\section{Methods}

\section{Participants}

The subjects of this study were selected as adult amateur golfers with more than one year of experience at Daejeon. Thirteen amateur golfers were enrolled and randomly divided into two groups. Subjects were included with the following criteria: (1) scoring average between 80 and 90, (2) driver shot distance greater than $200 \mathrm{~m}$. The exclusion criteria were (1) problems with musculoskeletal pain and function during golf swinging.

All participants were informed about the tests and the use of the results and were asked to sign a written statement in which they formally consented to the inclusion of the study. This study was conducted with the approval of the Institutional Review Board of Daejeon University (IRB No. 1040647-201706-HR-024-03).

\section{Procedure}

Using a repeated-measures crossover design, subjects were randomized to receive two sessions for two days of either a real-time visual feedback training (experimental) or general golf swing training (control), followed by a one training session on the first day, after which participants received the other training.

Prior to training, all subjects performed a 5-minute swinging practice session with a driver and iron club in the most comfortable addressing position to relax the tension and activate the muscles used during the golf swing. Drivers (1-wood) are used for long-distance fairway. Irons were the most versatile class and are used for a variety of shots. The driver and 7-iron club training and measurements were also randomly selected for each group. For the training of the experimental group, the Wii balance board (WBB) was placed under the subject and the monitor was placed $1 \mathrm{~m}$ ahead for

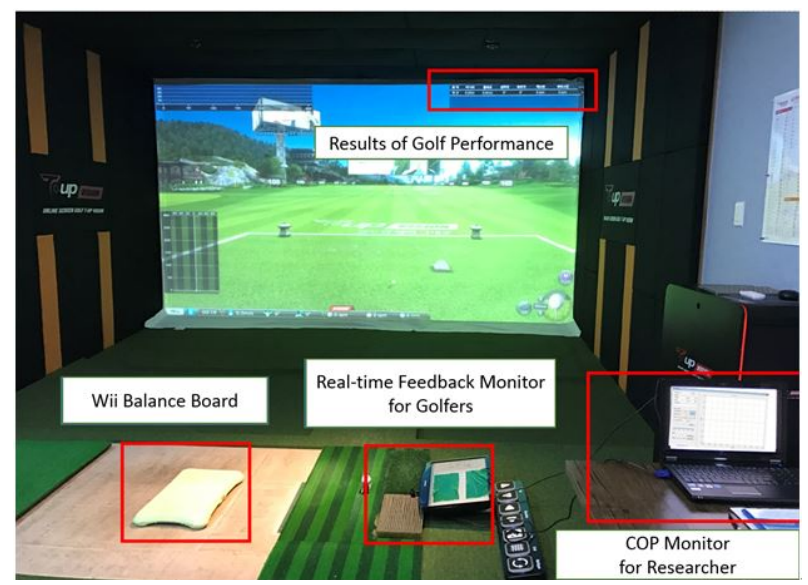

Figure 1. Real-time feedback setting during golf swing. COP: center of pressure. 
visual feedback (Figure 1).

Subjects were instructed to move the COP trajectory within $5 \mathrm{~cm}$ of the anterior and posterior on the front monitor screen during golf swing training on the WBB. After 10 practice sessions, they performed golf performance measurement on the ground [9]. The COP trajectory was assessed including all 10 practice sessions and the mean value was used. The golf performance measurement was repeated three times and its mean value was used, and both assessment and training sessions were performed at 24-hour intervals. The control group training session was performed in the same procedure without real-time visual feedback by each subject's own way. The control group performed self-guided learning using video feedback of his swing.

\section{Outcome measures}

\section{COP trajectory}

The COP trajectory measurement was assessed when the subjects were instructed to stand on the WBB while the subject swung. The WBB provides COP information which was collected continuously through the road-cells in the four corners of the WBB, and the data was collected through a computer device connected via Bluetooth. Sampling rate of the collected data was controlled by the associated software. In this study, data on COP velocity average $(\mathrm{cm} / \mathrm{s})$, COP path length $(\mathrm{cm})$, the medial lateral $(\mathrm{ML})$ distance $(\mathrm{cm})$, AP distance $(\mathrm{cm})$, ML range $(\mathrm{cm})$, and AP range $(\mathrm{cm})$ were all collected and measured. All data was sampled at $100 \mathrm{~Hz}$ and performed at a $10 \mathrm{~Hz}$ low-pass filter [18]. The collected data was analyzed with the Balancia program (Mintosys, Seoul, Korea).

\section{Golf swing performance}

In this study, the golf performance was measured using T-up Pro (Maumgolf, Seongnam, Korea). The high-speed $3 \mathrm{D}$ camera sensor measures ball and club movements up to 3,800 frames and physically analyzes the shot distance $(\mathrm{m})$, ball velocity $(\mathrm{m} / \mathrm{s})$, vertical launch angle $\left({ }^{\circ}\right)$, horizontal launch angle $\left({ }^{\circ}\right)$, backspin velocity (rpm), and side spin velocity (rpm).

\section{Data and statistical analysis}

For this study, the PASW Statistics ver. 22.0 (IBM Co., Armonk, NY, USA) was used for data analysis. Parametric distributions of the outcome were confirmed using the Shapiro-Wilk test. Statistical analyses of primary outcomes were performed using a mixed-model ANOVA, with main factors of time (pre- vs. post-testing), club (driver, iron), and training method (real-time visual feedback training, general golf swing training). Parameters during training were compared between pre- and post-training using paired t-tests or Wilcoxon signed rank as appropriate. The significance level was set at $\alpha=0.05$.

\section{Results}

The general characteristics of those who completed the training sessions are provided (Table 1), with no differences between participants who initially received experimental versus control group training sessions.

After training, the change in shot distance, ball velocity, and horizontal launch angle value in pre- and post-training were significantly different in both the driver and iron clubs in the experimental group. In the control group, the change in ball velocity, backspin rate, and side spin rate were significantly different only in the driver club. The mixed-model ANOVA performed for the golf swing performance measures a significant main effect of time for shot distance, ball velocity, horizontal launch angle, backspin rate, and side spin rate. There were no significant differences in group by time interaction and club by time interaction for all variables.

The subjects were trained using a driver club in which there was a significant change in the shot distance in the experimental group between pre- and post-training values $(p<0.05)$, and the mean change was significantly different between groups $(p<0.05)$. The ball velocity showed a statistically significant change in the experimental group and the control group $(p<0.05)$, and the mean change was significantly different between groups $(p<0.05)$. The horizontal launch angle and side spin velocity changed significantly in experimental group between pre- and post-training values $(p<0.05)$, and the mean changes were significantly different between groups $(p<0.05)$.

Table 1. General characteristics of subjects $(\mathrm{N}=13)$

\begin{tabular}{lc}
\hline Characteristic & Value \\
\hline Age $(\mathrm{yr})$ & $50.00(4.24)$ \\
Sex (male/female) & $13 / 0$ \\
Height $(\mathrm{cm})$ & $172.15(5.76)$ \\
Weight $(\mathrm{kg})$ & $76.23(12.08)$ \\
Golf career $(\mathrm{yr})$ & $5.31(4.82)$ \\
Handicap & $81.45(6.16)$ \\
\hline
\end{tabular}

Values are presented as number only or mean (SD). 


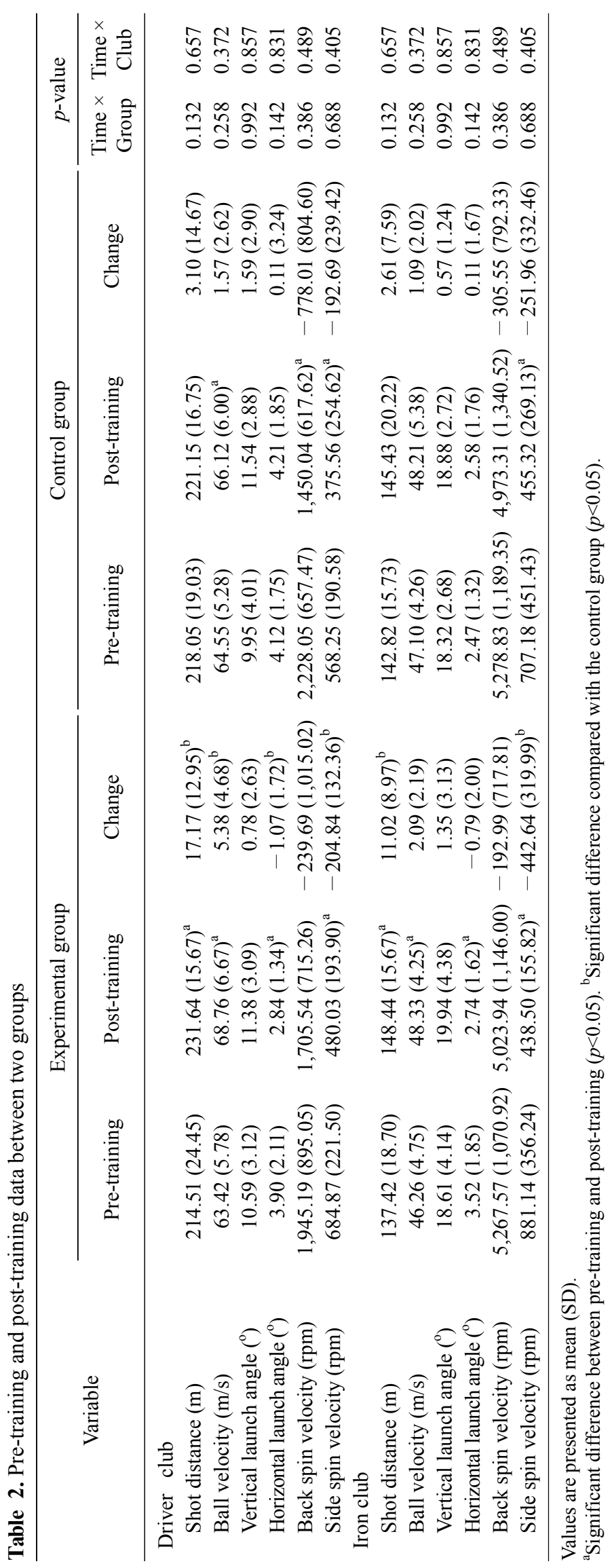


Table 3. COP parameters comparison between two groups

\begin{tabular}{lccc}
\hline \multicolumn{1}{c}{ COP parameter } & Experimental group & Control group & $p$-value \\
\hline Driver club & & & \\
COP velocity average $(\mathrm{cm} / \mathrm{s})$ & $28.50(7.40)$ & $32.39(5.65)$ & 0.147 \\
COP path length $(\mathrm{cm})$ & $67.83(13.50)$ & $72.19(15.29)$ & 0.448 \\
ML max distance $(\mathrm{cm})$ & $11.66(5.88)$ & $10.26(4.21)$ & 0.494 \\
ML min distance $(\mathrm{cm})$ & $-6.38(14.76)$ & $-10.35(5.21)$ & 0.369 \\
ML range $(\mathrm{cm})$ & $19.85(9.58)$ & $20.61(8.97)$ & 0.835 \\
AP max distance $(\mathrm{cm})$ & $3.93(1.11)$ & $6.44(2.31)$ & $0.002^{\mathrm{a}}$ \\
AP min distance $(\mathrm{cm})$ & $-3.41(0.85)$ & $-6.59(3.88)$ & $0.008^{\mathrm{a}}$ \\
AP range $(\mathrm{cm})$ & $7.34(1.55)$ & $13.02(6.02)$ & $0.003^{\mathrm{a}}$ \\
Iron club & & & \\
COP velocity average $(\mathrm{cm} / \mathrm{s})$ & $29.32(5.86)$ & $32.34(7.12)$ & 0.248 \\
COP path length $(\mathrm{cm})$ & $69.11(14.01)$ & $73.12(13.87)$ & 0.470 \\
ML max distance $(\mathrm{cm})$ & $9.70(4.75)$ & $10.19(4.75)$ & 0.797 \\
ML min distance $(\mathrm{cm})$ & $-9.69(5.13)$ & $-10.60(5.24)$ & 0.657 \\
ML range $(\mathrm{cm})$ & $19.39(9.53)$ & $20.79(9.62)$ & 0.713 \\
AP max distance $(\mathrm{cm})$ & $3.81(1.06)$ & $6.08(1.53)$ & $0.001^{\mathrm{a}}$ \\
AP min distance $(\mathrm{cm})$ & $-3.92(1.02)$ & $-5.45(3.56)$ & 0.150 \\
AP range $(\mathrm{cm})$ & $7.74(1.56)$ & $11.53(4.86)$ & $0.013^{\mathrm{a}}$ \\
\hline
\end{tabular}

Values are presented as mean (SD)

COP: center of pressure, ML: medial lateral, max: maximum, min: minimum, AP: anterior posterior.

${ }^{a}$ Significant difference compared with the control group $(p<0.05)$.

When using an iron club, the shot distance changed significantly in experimental group between pre- and posttraining $(p<0.05)$, and the mean change was significantly different between groups $(p<0.05)$. There was a significant change in ball velocity in the experimental group and the control group $(p<0.05)$. The side spin velocity was a statistically significant in the experimental group and the control group $(p<0.05)$, and the mean change was significantly different between groups $(p<0.05)$ (Table 2$)$.

Comparing COP parameters between groups, there was a significant difference in AP max distance, AP min distance, and AP range when using the driver club. During training sessions using the iron club, there was a significant difference in AP max distance and AP range (Table 3).

\section{Discussion}

The purpose of this study was to measure the improvement of the performance of golfers through real-time visual feedback training on golf player's weight shift movements during golf swinging. The main findings of the study showed significant improvements in shot distance, ball velocity, and horizontal launch angle and side spin rate after the swing training with real-time visual feedback.

In this study, WBB was used to provide visual feedback in real-time. Vision is the most sensitive form of human motion and it is the most dependent sense when performing body movements. The sense of sight is the best external receptor for accepting exteroceptive information, which is required for motion planning and motion control. Learning through vision, which is the exteroceptor for motor planning and control, is said to be useful because it represents motion in memory through visual information [19].

It is commonly believed that specific strength and conditioning programmes may be able to maximize the distance of a golf shot and thus, to improve performance in golf. In relation to golf performance enhancement, the major proposed benefit of a conditioning programme is thought to be increased shot distance (especially of the drive) through increasing the joint range of motion [20], muscle strength, power and balance [21], and muscular and aerobic endurance [22]. In this study, shot distance increased as a result of weight shift training, which indicates that training is also necessary to improve golf performance and shot distance.

After training, the experimental group showed significant changes in horizontal launch angle and side spin velocity, which influenced shot accuracy improvement. The aerodynamic flight of the golf ball is dependent on the initial velocity of the ball and the spin of the ball as it travels through the air. While the initial velocity is most important for the total 
distance the ball flies with greater velocity producing greater distance, it is the spin of the ball which has the most interesting effects on its flight path. The Magnus effect of the spin of the ball produces both lateral and upward lift forces during its flight $[23,24]$. The direction and velocity of side spin affects the sideways motion of the ball during its flight. As viewed from the top, clockwise spin causes the ball to 'slice' to the right and counter-clockwise spin causes the ball to 'hook' to the left as shown. Sometimes side spin is intentionally applied to the ball to produce a particular trajectory but in general, side spin has an undesirable effect on the shot and decreases the distance the ball will fly [25].

The typical strategy for golf training consists of high volume repetition with an emphasis on a large variety of isolated swing characteristics. The student is frequently instructed to maintain consistent performance in each swing with absolute invariance. Based on dynamical systems and motor control schema perspectives, it is argued that golfers can learn a more reliable swing by exploring swing parameters and focusing on higher order control principles that reduce the vast number of degrees of freedom [26]. In addition, as a proficient golf swing is a key element of success in golf, many golfers make significant effort in improving their stroke mechanics.

During a golf swing, only 5\%-19\% of the golfer's weight is supported on the right foot during backswing, and the rest of the weight weight is moved to the left foot. Thus, an efficient swing cannot be achieved without the ability to maintain stable balance or proper weight shift ability. In order to transmit the maximum momentum of the head to the golf ball, the center of the ball and the club head must match in the exact impact position and direction [27]. Amateur golfers have higher muscle activity and $50 \%$ more swing torque than professional golfers during swing, but the swing is irregular so that they do not create the exact impact moment [28]. The professional golfers had superior dynamic balance ability, achieved by controlling the COP excursion to compensate for the increased variation of the center of mass, leading to a more stable swing mechanism than that of the amateur golfers. This study provides quantitative information for the evaluation of dynamic balance control during the golf swing [29].

Limitations of this study were an indoor driving range training, and only using driver and 7-iron clubs. Future studies will be needed in various environments and other clubs. It is also necessary to study kinematics and kinematical variables through electromyography and motion analysis.
In this study, real-time feedback training using weight shifting movement improved golf shot distance and accuracy, which will be effective in increasing golf performance. It can also be used as an index for golf player ability.

\section{Conflict of Interest}

The authors declared no potential conflicts of interest with respect to the authorship and/or publication of this article.

\section{References}

1. Jorgensen Jr T. On the dynamics of the swing of a golf club. Am J Phys 1970;38:644-51.

2. Wells GD, Elmi M, Thomas S. Physiological correlates of golf performance. J Strength Cond Res 2009;23:741-50.

3. Fletcher IM, Hartwell M. Effect of an 8-week combined weights and plyometrics training program on golf drive performance. $\mathrm{J}$ Strength Cond Res 2004;18:59-62.

4. Gordon BS, Moir GL, Davis SE, Witmer CA, Cummings DM. An investigation into the relationship of flexibility, power, and strength to club head speed in male golfers. J Strength Cond Res 2009;23:1606-10.

5. Thompson C. Effect of muscle strength and flexibility on club-head. In: Eric T, editor. Science and golf IV. Abingdon: Routledge; 2012. p. 35-44.

6. Egret CI, Vincent O, Weber J, Dujardin FH, Chollet D. Analysis of $3 \mathrm{D}$ kinematics concerning three different clubs in golf swing. Int J Sports Med 2003;24:465-70.

7. Hrysomallis C. Balance ability and athletic performance. Sports Med 2011;41:221-32.

8. Chu Y, Sell TC, Lephart SM. The relationship between biomechanical variables and driving performance during the golf swing. J Sports Sci 2010;28:1251-9.

9. Barrentine SW, Fleisig GS, Johnson H, Woolley TW. Ground reaction forces and torques of professional and amateur golfers. London: Science and Golf II Proceedings of the World Scientific Congress of Golf; 1994.

10. Thompson CJ, Cobb KM, Blackwell J. Functional training improves club head speed and functional fitness in older golfers. J Strength Cond Res 2007;21:131-7.

11. Tsaklis PV, Grooten WJ, Franzén E. Effects of weight-shift training on balance control and weight distribution in chronic stroke: a pilot study. Top Stroke Rehabil 2012;19:23-31.

12. Cheng PT, Wang CM, Chung CY, Chen CL. Effects of visual feedback rhythmic weight-shift training on hemiplegic stroke patients. Clin Rehabil 2004;18:747-53.

13. Gerbino PG, Griffin ED, Zurakowski D. Comparison of standing balance between female collegiate dancers and soccer players. Gait Posture 2007;26:501-7.

14. Yoo JS, Ha HG, Jeong JR, Ko YJ, Lee WH. Physical therapist perception survey for muscle re-education through visual feedback obtained from rehabilitative ultrasound imaging. Phys Ther Rehabil Sci 2016;5:47-52. 
15. Park JH, Chung Y. The effects of providing visual feedback and auditory stimulation using a robotic device on balance and gait abilities in persons with stroke: a pilot study. Phys Ther Rehabil Sci 2016;5:125-31.

16. Loughlin PJ, Redfern MS. Spectral characteristics of visually induced postural sway in healthy elderly and healthy young subjects. IEEE Trans Neural Syst Rehabil Eng 2001;9:24-30.

17. Uchiyama M, Demura S. Low visual acuity is associated with the decrease in postural sway. Tohoku J Exp Med 2008;216:277-85.

18. Park DS, Lee DY, Choi SJ, Shin WS. Reliability and validity of the balancia using wii balance board for assessment of balance with stroke patients. J Korea Acad Ind Coop Soc 2013;14:2767-72.

19. Lee AM, Keh NC, Magill RA. Instructional effects of teacher feedback in physical education. J Teach Phys Educ 1993;12:228-43.

20. Neal RJ, Abernethy B, Parker AW, Moran MJ. The influence of club length and shot distance on the temporal characteristics of the swings of expert and novice golfers. In: Cochran AJ, editor. Science and golf I. Proceedings of the First World Scientific Congress on Golf; 1990 Jul 9-13; St Andrews. London. E \& FN Spon; 1990. p. 36-42.

21. Reyes MG, Munro M, Held B, Gebhardt WJ. Maximal static contraction strengthening exercises and driving distance. In: Thain, editor. Science and golf IV: proceedings of the 2002
World Scientific Congress of Golf. London: Routledge; 2002. p. 45-53.

22. Hume PA, Keogh J, Reid D. The role of biomechanics in maximising distance and accuracy of golf shots. Sports Med 2005; 35:429-49.

23. Briggs LJ. Effect of spin and speed on the lateral deflection (curve) of a baseball; and the Magnus effect for smooth spheres. Am J Phys 1959;27:589-96.

24. Johnson D. A three-dimensional forward dynamic model of the golf swing. Waterloo, Ontario: University of Waterloo; 2015.

25. McPhee JJ, Andrews GC. Effect of sidespin and wind on projectile trajectory, with particular application to golf. Am J Phys 1988;56:933-9.

26. Knight CA. Neuromotor issues in the learning and control of golf skill. Res Q Exerc Sport 2004;75:9-15.

27. Koenig G, Tamres M, Mann RW. An analysis of the kinetics and kinematics of the golf swing. Res Q Exerc Sport 1993;1:420-49.

28. Gluck GS, Bendo JA, Spivak JM. The lumbar spine and low back pain in golf: a literature review of swing biomechanics and injury prevention. Spine J 2008;8:778-88.

29. Choi A, Kang TG, Mun JH. Biomechanical evaluation of dynamic balance control ability during golf swing. J Med Biol Eng 2016;36:430-9. 